\title{
A Tutela do Animal Doméstico no Âmbito das Constituições Federais Brasileiras de 1824 a 1988
}

\section{The Guardianship of Domestic Animals under the Brazilian Federal Constitutions from 1824 to 1988}

\author{
Nilsen Aparecida Vieira Marcondes \\ Prefeitura Municipal de São José dos Campos. SP, Brasil. \\ E-mail: nilsenmarcondes@gmail.com
}

\begin{abstract}
Resumo
Objetiva-se discutir neste breve intróito retrospectivo de revisão de normatizações constitucionais pátrias a tutela do animal doméstico. Esta síntese reflexiva sobre a tutela do animal doméstico brasileiro no âmbito constitucional se apresenta quanto à forma de abordagem do assunto, como qualitativo, no que tange a modalidade investigativa como básico, do ponto de vista de seus objetivos, como descritivo, com relação aos procedimentos técnicos, qualifica-se como documental e bibliográfico. Conclui-se que os delineamentos, os limites, bem como os avanços na conquista da tutela animal e consequentemente do animal doméstico demonstram o quanto o reconhecimento de tal questão é socialmente construído. Além disso, a expansão, a solidificação e o desenvolvimento contínuo também da vida humana e da sociedade implicam necessariamente na preservação e na ampliação de acesso um direito fundamental nominalmente reconhecido pela Constituição Federal de 1988 como direito ao ambiente ecologicamente equilibrado no qual se insere evidentemente a fauna, ou seja, os animais domésticos, domesticados, silvestres e exóticos.
\end{abstract}

Palavras-chave: Animal Doméstico. Tutela. Constituições Federais. Brasil.

\begin{abstract}
The objective of this brief retrospective introjective review of constitutional norms is to discuss the protection of domestic animals. This reflexive synthesis about the protection of the Brazilian domestic animal in the constitutional scope presents itself as to the way of approaching the subject, as qualitative, in what refers to the research modality as basic, from the point of view of its objectives, as descriptive, with respect to the procedures technicians, qualifies as documentary and bibliographical. It is concluded that the delineations, the limits, as well as the advances in the conquest of the animal guardianship and consequently of the domestic animal demonstrate how much the recognition of such question is socially constructed. In addition, the expansion, solidification and continuous development of human life and society necessarily imply the preservation and expansion of access to a fundamental right nominally recognized by the Federal Constitution of 1988 as a right to an environmentally balanced environment in which the animal, domesticated, wild and exotic animals.
\end{abstract}

Keywords: Domestic Animals. Guardianship. Federal Constitutions. Brasil.

\section{Introdução}

O objetivo deste artigo é refletir sobre a presença ou ausência do fator protetivo dos animais domésticos no âmbito da diversas Constituições Federais que ocuparam o cenário nacional brasileiro dos seus primórdios à contemporaneidade.

Diante do exposto considera-se, portanto, a relevância do estudo para a área do conhecimento escolhida uma vez que a existência desse arcabouço legislativo voltado à temática da defesa e proteção dos animais exige uma: (a) contínua fiscalização para que seus dispositivos sejam efetivamente aplicados; e b) permanente averiguação das tensões e/ ou possibilidades advindas da efetivação ou não de tais dispositivos frente às situações decorrentes de ações e/ou omissões antrópicas tais como maus-tratos, abandono e/ou negligências para com os animais.

Um segundo motivo atribuidor de relevância ao estudo para a área do conhecimento escolhido situa-se na eventual possibilidade de o mesmo poder contribuir no adensamento da literatura já existente a respeito da importância da promoção da tutela dos animais, particularmente do doméstico em todo o território nacional brasileiro.

Entende-se por animais domésticos aqueles de convívio com ser humano, dele dependentes, e que não repelem o jugo humano (SÃO PAULO, 2005). Portanto, na direção de tal conceituação é preciso levar em consideração três importantes aspectos.

Primeiro, que o animal considerado como "doméstico" é "dependente" do ser humano o que justifica uma especial atenção por parte deste ser humano para com ele principalmente com aquele animal doméstico que reside no ambiente urbano.

Segundo que existem outras espécies de animais além do doméstico quais sejam os: domesticados, silvestres e exóticos os quais não se configuram como tão dependentes (os domesticados) ou nada dependentes (os silvestres e exóticos) da espécie humana.

A definição conceitual de animal doméstico, domesticado, silvestre e exótico adotada neste trabalho advém da Lei do Estado de São Paulo no 11.977 de 2005. 
E, terceiro que ao se levar em consideração tal conceituação emergente da legislação estadual acrescida de um arcabouço legislativo federal voltado à temática da tutela animal independentemente da espécie - doméstico, domesticado, silvestre e exótico -, justifica-se uma reflexão mais aprofundada em torno da possibilidade de implementação de políticas públicas voltadas à defesa e proteção dos animais nos municípios brasileiros, principalmente naqueles munícipios em que os índices apontam para elevadas situações de maus tratos, negligência e/ou abandono.

$\mathrm{O}$ animal doméstico, assim como todas as demais espécies, é portador de sensações como de desconforto físico ou mental. Além disso, sente fome e sede. Trata-se de um ser senciente ${ }^{1}$ e vulnerável, cuja sobrevivência depende dos seus tutores. Portanto, toda e qualquer situação que cause ao animal doméstico desconforto físico (ferimentos diversos consequente da fragilidade de sua situação de saúde, de fraturas sofridas e/ou de agressões que lhe foram imputadas decorrentes de contatos com outros animais ou com seres humanos) e/ou desconforto mental (abandono) deve ser objeto de atenção, tendo em vista que a ação ou omissão humana traz consequências para a vida do animal, particularmente da espécie doméstica.

De acordo com Muraro e Alves (2014, p.5) o animal doméstico: "É muito carinhoso e fiel, possuindo uma característica peculiar, qual seja, a gratidão. O seu habitat natural é ao lado do seu dono, sendo protegido de todas as formas".

Situações de maus-tratos voltados especialmente aos animais domésticos a serem combatidos por meio de uma maior eficácia e efetividade na fiscalização e aplicação das normatizações podem ser classificadas como: abandonar, espancar, golpear, mutilar e envenenar; manter preso permanentemente em correntes; manter em locais pequenos e anti-higiênicos; não abrigar do sol, da chuva e do frio; deixar sem ventilação ou luz solar; não dar água e comida diariamente; negar assistência veterinária ao animal doente ou ferido; obrigar a trabalho excessivo ou superior a sua força; utilizar animal em shows que possam lhe causar pânico ou estresse; promover violência como rinhas de galo, farra-doboi etc. (BRASIL, 2016, p.2).

$\mathrm{Na}$ sociedade brasileira, ao se refletir sobre a tutela do animal doméstico no âmbito constitucional, compreende-se que apesar dos limites inerentes a alguns momentos históricos específicos o que culminou na completa inexistência de dispositivos que tratassem do assunto nas seis primeiras Constituições Federais (BRASIL, 1824, 1891, 1934, 1937, 1946, 1967) houve não obstante um caminhar na direção do reconhecimento e fortalecimento da necessidade de se defender e proteger a espécie animal como verificado na última e contemporânea Constituição Federal de 1988
(BRASIL, 1988).

\section{Desenvolvimento}

\subsection{Metodologia}

Este estudo se apresenta quanto à forma de abordagem do assunto, como qualitativo; no que tange a modalidade investigativa como básico; do ponto de vista de seus objetivos, como descritivo; com relação aos procedimentos técnicos, qualifica-se como documental e bibliográfico; no que diz respeito aos instrumentos de coleta de dados caracteriza-se pela (i) seleção e leitura das normatizações constitucionais, (ii) organização das informações coletadas, e (iii) análise e discussão das informações de cunho documental; em se tratando da corrente epistemológica adotada pauta-se no construtivismo; no tocante a perspectiva teórica priorizada tem-se a investigação crítica; e por fim no que concerne ao referencial analítico para análise e interpretação das normatizações utiliza-se da análise de conteúdo (PEROVANO, 2016).

\subsection{Discussão}

\subsubsection{Introito retrospectivo da tutela animal}

No período pré-histórico da humanidade, os animais eram considerados e tratados como mercadorias. Ao final de sua vida útil, ou seja, de sua serventia utilitarista para o homem os animais eram descartados. Ressalta-se, portanto que o foco da atenção humana não se voltava à vida do animal, mas sim nos interesses pessoais, mercantilistas e práticos do homem (MURARO; ALVES, 2014).

Muraro e Alves (2014, p.6) destacam que:

No início da relação entre seres humanos e animais, havia somente relação de trabalho entre eles, ou seja, a única finalidade que o animal possuía era satisfazer os interesses do seu dono, ficando à disposição, a qualquer momento, e sobre o seu domínio.

Não obstante esse passado remoto de completo descaso para com a causa animal, gradativamente o pensamento humano foi se alterando no sentido da valoração do animal. Fato este que ainda se encontra em processo de desenvolvimento. Neste sentido, destacam-se dois episódios. O primeiro deles diz respeito ao registro da ligação afetiva entre um ser humano e um animal o qual data de 12 mil anos, comprovado pelos fósseis de uma senhora, de aproximadamente 60 anos, abraçada a um filhote de lobo encontrados em Israel (CAMPOS NETO, 2005).

O segundo episódio é datado de 150 mil anos e nele descrevese o fato de que:

os lobos seguiam um bando de nômades que saíam de suas cavernas para a caça, dando início a determinada convivência que se estreitou há cerca de $10 \mathrm{mil}$ anos, quando o cão, descendente, passou a ser protegido, isto é, entrando em suas cavernas, tornando-se, na História da Humanidade, amigos 


\section{fiéis (CAMPOS NETO, 2005, p.249).}

Na evolução desse processo valorativo do animal por parte do homem, tem-se a informação de que um dos documentos mais longínquos referente à mudança de paradigma no que tange à causa animal alude à Bíblia Católica (BÍBLIA, 1998).

Particularmente no que se refere à questão protetiva foram encontrados quatro registros e todos eles elencados no primeiro testamento. A seguir destacam-se três citações no Livro denominado Gênesis e uma citação no Livro chamado Provérbios (BÍBLIA, 1998).

A primeira delas anuncia que após a criação da espécie animal Deus se volta para ela e a abençoa conforme se pode ler nas seguintes afirmações: "Deus disse: Pulem as águas de uma multidão de seres vivos e voem aves sobre a terra [...]. E Deus viu que isso era bom. E Deus os abençoou [...]" (BÍBLIA GÊNESIS 1:20-22, 1998, p.49).

A segunda citação evidencia a aliança que Deus faz com todos os seres vivos da terra independente de ser humano ou ser animal. Eis o registro: "Disse [...] Deus a Noé e a seus filhos $[\ldots]$ vou fazer uma aliança $[\ldots]$ com todos os seres vivos [...] as aves, os animais domésticos, todos os animais selvagens $[\ldots]$ desde todos aqueles que saíram da arca até todo animal da terra" (BÍBLIA GÊNESIS 9:8-10,_1998, p.56).

Por fim, a terceira citação do Gênesis reforça a questão da aliança estabelecida entre Deus e os animais estabelecendo um sinal concreto para isso, qual seja, a presença do arcoíris sobre as nuvens. Portanto, na sequência lê-se que toda vez que o arco-íris estiver nas nuvens, Deus olhará para ele e se lembrará da aliança eterna que fez com todos os seres vivos de todas as espécies que habitam na terra: "Eis o sinal da aliança que eu faço [...] com todos os seres vivos [...] ponho o meu arco nas nuvens [...] e me lembrarei da aliança que fiz convosco e com todo ser vivo de toda espécie. [...] Este é o sinal da aliança que faço entre mim e todas as criaturas que estão na terra”. (BÍBLIA GÊNESIS 9:12-17,_1998, p.56).

Como se pode depreender desta leitura contextualizada no âmbito dos escritos católicos, os textos evidenciam que os animais além de serem desejados, foram também criados por Deus e abençoados por Ele. E a simples presença desses animais na terra, nas águas e no ar envolveu a Deus de um sentimento positivo ao ponto de afirmar que "isso era bom". E ainda, se não bastasse a "criação", a "benção" o sentimento "positivo" que tais criaturas despertam no seu Criador, Ele faz questão de também estabelecer com os mesmos uma aliança, ou seja, um relacionamento. E a palavra relacionamento implica em continuidade, continuidade na defesa de que todos os seres vivos sejam eles humanos ou animais possuem idêntico direito à existência. Portanto quando o assunto é a causa animal expressões e palavras como "desejo de criação", "benção", "júbilo pela simples existência" e "aliança" se evidenciam neste Livro considerado como sagrado pelos adeptos do catolicismo.

Em se tratando ainda do primeiro testamento tem-se agora uma citação do Livro Provérbios. Nesse Livro situa-se o fato de que a pessoa qualificada como justa tem consideração pela vida dos seus animais conforme se pode verificar in verbis: "O justo cuida das necessidades de seu gado, mas cruéis são as entranhas do ímpio" (BÍBLIA PROVÉRBIOS 12:10, 1998, p.791). A leitura desta frase bíblica evidencia uma correlação significativa entre duas realidades que se coadunam: de um lado aquilo que se considera como justo enquanto qualidade emergente de uma personalidade humana e por outro lado o desejo de proteger o animal não humano.

Portanto, o que emerge desta citação é que todos os seres sencientes merecem amor, carinho, respeito e proteção. É interessante destacar ainda que um traço de personalidade caracterizado como cruel não apresenta o mesmo sentimento de empatia pela vida do animal não humano. É o que afirma o escrito supracitado: um dos registros mais remotos que se tem conhecimento a respeito da preservação da fauna terrestre.

Outro documento igualmente longínquo referente à causa animal se refere aos papiros do Livro dos Mortos dos egípcios. Nas páginas desse Livro são descritos comportamentos respeitosos dos egípcios não somente para com os animais, mas também para com as demais realidades que dizem respeito à natureza como a água e o solo. A proteção dos animais e a conservação da água e do solo eram tidas pelos egípcios como forma de agradar ao grande Deus, para eles denominado de Osíris. Eis alguns exemplos dos escritos nos papiros egípcios citados por Levai (1998, p.13): "Não matei os animais [...] Não sujei a água [...] Não usurpei a terra [...] Nunca apanhei com redes os pássaros [...] Sou puro, ó Grande Osíris. Sou puro. Sou puro".

$\mathrm{Na}$ esteira dos defensores da causa animal têm-se também os escritos e as ações de alguns pensadores que marcaram presença na história da humanidade. Dentre eles cita-se, por exemplo, Siddhartha Gautama, popularmente conhecido como Buda foi um príncipe de uma região no sul do atual Nepal. Ele, após renuncia ao trono, voltou-se à busca da erradicação das causas do sofrimento humano, bem como de todos os seres sencientes existentes no planeta terra (CAMPOS NETO, 2005). Buda assumiu uma postura diversa à morte de qualquer ser vivo fosse ele "bicho ou gente" (LEVAI, 1998). O primeiro Mandamento Budista enuncia justamente o respeito que se deve adotar perante a vida. Nas palavras do mestre indiano citadas Levai (1998, p.14): “Tende piedade de todas as criaturas vivas e dessa forma o fogo de vossa vida se extinguirá e mergulhareis numa abençoada eternidade de paz [...] Não matarás nenhuma criatura vivente".

Pitágoras atuava como matemático e astrônomo na ilha de Samos onde viveu. Esse filósofo grego, assim como Aristóteles, se debruçou sobre a causa animal (CAMPOS NETO, 2005). Pitágoras era vegetariano e se posicionava como contrário a todo e qualquer utilização de animais para alimentação ou sacrifício religioso (SANTANA, 2006). Nas palavras dele, "Quem semeia a morte não pode colher o amor; enquanto o homem continuar a ser o destruidor impiedoso dos 
animais não terá nem saúde, nem alegria, nem tranquilidade de espírito". (LEVAI, 1998, p.14).

Sócrates outro filósofo também grego viveu numa época em que se instalava o conflito entre a moral e a ética ocasionando o surgimento do antropocentrismo. Tratava-se de um período no qual o ser humano sentia-se superior e por isso proprietário dos demais seres vivos existentes na terra por uma única razão: "somente ele tinha o poder do pensamento e da fala” (MURARO; ALVES, 2014, p.6).

Não obstante, Sócrates fazer parte desse período histórico e sua célebre afirmação "Conhece-te a ti mesmo" ter sido o marco inicial para a consolidação do antropocentrismo, ele se recusava a alimentar-se de carne. Em defesa do hábito alimentar que possui (vegetarianismo), Sócrates afirmava que nos animais ele via a si mesmo e também os considerava como indivíduos. Suas afirmações evocavam o seguinte: "Não requereria este hábito de comer animais que abatêssemos animais que reconhecemos como indivíduos, em cujos olhos vemos a nós mesmos refletidos, poucas horas antes de nossa refeição [...]" (MURARO; ALVES, 2014, p.6-7).

Aristóteles um filósofo também grego e que se dedicou de forma meticulosa no estudo dos animais redigindo uma classificação das espécies. Este trabalho catalográfico tem sua relevância na medida em que atribuiu a Aristóteles o título de precursor da ciência voltada ao reino animal, denominada zoologia (LEVAI, 1998; CAMPOS NETO, 2005). A “ideia aristotélica era a de que o universo opera de acordo com um plano divino, e que os seres são criados em benefício uns dos outros (SANTANA, 2006).

Partindo-se agora de uma ordem cronológica crescente, após a instituição do calendário cristão, ou seja, após o nascimento de Cristo têm-se também algumas pessoas que merecem destaque quando o assunto é proteção e defesa dos animais.

Francisco de Assis, considerado como santo pela Igreja Católica, foi um árduo defensor dos animais, bem como de tudo o que existe na natureza. É de autoria desse santo italiano o escrito "Cântico das Criaturas" em que sob a forma de um hino declara seu amor por todos os seres da terra que possuem vida. São Francisco é reconhecido como santo padroeiro dos animais. E, na data de sua morte, quatro de outubro, é comemorado o dia da Ecologia e o Dia Universal dos Animais (LEVAI, 1998; CAMPOS NETO, 2005). Francisco de Assis fundou a Ordem dos Frades Menores e é considerado como o maior inspirador da contemporânea definição ambientalista dos animais como criaturas de Deus e por isso dignas de respeito por parte do ser humano (CAMPOS NETO, 2005).

A vida de São Francisco de Assis está repleta de acontecimentos que evidenciam o seu amor pelos animais. Santana (2006, p.19) cita alguns exemplos: “[...] seja quando liberta um coelho capturado em uma armadilha, devolve à agua peixes que se encontravam presos em uma rede de pesca, pede mel para dar às abelhas no inverno ou amansa um lobo assassino e o transforma num animal doméstico no povoado de Gubbio".

Roque de Montpellier, canonizado pela Igreja Católica, é reconhecido como São Roque. Seu amor pelos felinos era grande e conviveu com dezenas deles. Ele é reconhecido como protetor espiritual dos animais, principalmente dos cães domésticos e selvagens (CAMPOS NETO, 2005).

Leonardo Da Vinci, italiano, pintor, escultor, biólogo e matemático que se destacou na época da renascença, assumiu uma preciosa postura em prol dos animais a qual enriqueceu os estudos até então realizados no âmbito da proteção de todos os seres sencientes. Suas observações criteriosas, particularmente dos mamíferos e insetos trouxeram reflexos positivos para a compreensão da vida dos animais. São de Leonardo da Vinci as palavras: Virá o dia em que a matança de um animal será considerada crime tanto quanto o assassinato de um homem. (LEVAI, 1998, p.14). Da Vinci "foi o primeiro cientista da Idade Moderna que estudou com minúcias os mamíferos, contribuindo demasiadamente à Medicina Veterinária" (CAMPOS NETO, 2005, p.248).

O padre Antônio Vieira, nascido em Portugal transferiu-se para o Brasil onde permaneceu até a sua morte, também se apresentava como defensor dos animais. É de sua autoria o escrito de um antológico tratado sobre o jumento intitulado “O Jumento, Nosso Irmão". Esse missionário vem, portanto, a somar-se a todos aqueles que se empenham na defesa da causa animal (LEVAI, 1998, p.15).

Immanuel Kant, filósofo prussiano, igualmente mostra preocupação de ordem moral e ética valorativa no que diz respeito à causa animal. Nas palavras dele: "Podemos julgar o coração de um homem pela forma como ele trata os animais" (FRANCO, 2016, p.8).

Jeremy Benthan filósofo e jurista londrino defendia que os animais eram dotados da capacidade de sentir prazer e dor. E, justamente pelo fato dos animais experimentarem tais sensações caberia ao ser humano o dever de reduzir o sofrimento imposto ao animal consequente de sua ação ou omissão. Para Jeremy, portanto, qualquer ação humana capaz de minimizar tal sofrimento animal seria considerada como válida e eficiente (MURARO; ALVES, 2014).

Henry Salt, artista, diplomata e egiptólogo britânico se declarava também a favor dos animais. São suas as afirmações de que se os seres humanos têm direitos, os animais igualmente os possuem, na medida em que se reconhece o direito como "um sentido de justiça que marca as fronteiras onde a aquiescência acaba e a resistência começa; uma demanda pela liberdade de viver sua própria vida, à necessidade de respeitar a igual liberdade das outras pessoas" (SANTANA, 2006, p.117).

Paralelamente ao surgimento do período iluminista na França, muitos pensadores adeptos desta corrente filosófica da época começaram a criticar a forma como os animais eram tratados até então, qual seja como meros objetos (MURARO; ALVES, 2014).

Diante disso, os estudos voltados às realidades da natureza 
começaram a adotar perspectivas científicas e neste contexto o aporte teórico consolidado pelos alemães Friedrich Wilhelm Heinrich Alexander von Humboldt e Ernst Heinrich Philipp August Haeckel contribuiu proficuamente. Inclusive Haeckel é considerado como pai da ecologia moderna. (LEVAI, 1998; CAMPOS NETO, 2005).

$\mathrm{Na}$ esteira dessa evolução da perspectiva científica dos estudos da natureza, o naturalista inglês Charles Darwin também colaborou. Darwin após a visita realizada nas Ilhas Galápagos no ano de 1835, formulou a Teoria da Evolução das Espécies, um detalhado estudo dos seres vivos em função do ambiente em que vivem (LEVAI, 1998; CAMPOS NETO, 2005).

Abraham Lincoln, político norte-americano, também reconhece os animais como merecedores de atenção e de direitos que privilegiem sua existência e bem-estar. Suas palavras são as seguintes: "Não me interessa nenhuma religião cujos princípios não melhoram nem tomam em consideração as condições dos animais". (FRANCO, 2016, p.8).

Mohandas Karamchand Gandhi, conhecido como Mahatma Ghandi, um líder indiano pacifista e advogado evocava a piedade para com todos os animais. Para ele esses seres indefesos, vítimas da violência e crueldade humanas, não têm condições para resistir (LEVAI, 1998). Os ensinamentos hindus defendem que para se viver "feliz, com saúde e amor" faz-se necessário o respeito pelos animais (CAMPOS NETO, 2005, p. 247).

Albert Schweitzer teólogo, organista, filósofo e médico, nasceu em Kaysersberg, França, na época, parte do Império Alemão. O prêmio Nobel da Paz do ano de 1945 foi dedicado a ele. São suas palavras as que seguem: "Quando o homem aprender a respeitar até o menor ser da criação, seja animal ou vegetal, ninguém precisará ensiná-lo a amar seu semelhante". (PENSADOR, 2018, s/p.).

Albert Einstein, um físico alemão, também trouxe contribuições à causa animal. Suas reflexões em torno das similitudes entre os animais e os seres humanos rendeu sua defesa na convicção de que tanto um quanto o outro possuíam os mesmos direitos e de forma igualitária. Einstein era adepto do vegetarianismo, afirmando não ter coragem de comer carne porque não conseguia diferenciar a carne humana da carne animal (MURARO; ALVES, 2014, p. 8). “[...] se as abelhas desaparecerem da face da terra a humanidade terá apenas mais quatro anos de existência, sem abelhas não há polinização, não há reprodução da flora, sem flora não há animais, sem animais não haverá raça humana". (MURARO; ALVES, 2014, p.8).

Pablo Picasso, pintor espanhol, é autor da seguinte declaração: "No dia em que o homem compreender ser filho da Natureza, irmão dos bichos da terra, dos pássaros do céu e dos peixes do mar, neste dia ele compreenderá sua própria insignificância. Será mais humano, mais simples e solidário" (CAMPOS NETO, 2005, p.245).

Hans Kelsen jurista e filósofo tcheco também se mostrava sensível à causa animal na medida em que não se melindrava ao defender seus pensamentos a respeito da compreensão que possuía de que os animais também são sujeitos de direitos. E isso porque Kelsen entendia que a relação jurídica não acontecia entre o sujeito de dever e o sujeito de direito, "mas entre o próprio dever jurídico e o direito reflexo de um dever jurídico, posto que a relação jurídica é sempre uma relação entre normas: uma norma que obriga o devedor, e outra que faculta ao seu titular o poder de exigi-lo". (SANTANA, 2006, p. 117).

No contexto do cinema e da televisão, alguns personagens também se destacam na defesa da causa animal. JacquesYves Cousteau, oficial da marinha francesa, documentarista, cineasta, oceanógrafo é um deles. Cousteau navegou pelos mares do planeta terra produzindo diversas reportagens sobre a fauna e a flora aquática que ficaram mundialmente conhecidas como séries educativas de televisão (LEVAI, 1998; CAMPOS NETO, 2005).

Outra personagem que emerge deste contexto e na defesa da causa animal é a atriz Brigitte Bardot a qual instituiu uma Fundação Internacional de Amparo aos Animais, localizada na França (LEVAI, 1998; CAMPOS NETO, 2005).

Valerie Jane Morris Goodall, primatóloga, etóloga e antropóloga britânica, também se destaca na causa animal. Essa cientista coordena pesquisas no Congo e em Gombe, na Tânzania referente à vida social e familiar dos chimpanzés. Os resultados das pesquisas realizadas no decorrer de 40 anos contribuíram para o avanço dos conhecimentos atinentes à aprendizagem social, ao raciocínio e a cultura dos chimpanzés selvagens. Ocupa ainda a função de mensageira da paz das Nações Unidas. Sua atuação em prol dos animais é reconhecida internacionalmente tendo inclusive recebido vários prêmios acadêmicos (CAMPOS NETO, 2005).

Enfatizam-se também as pesquisas científicas da primatologista Jessica Tombs na preservação de chimpanzés e de Diane Doran voltadas à preservação de gorilas. Destacase ainda a jornalista e naturalista Lyndal Davies que percorre o planeta terra, incluindo a região da Amazônia, a procura de animais em extinção e/ou fora das florestas e habitats naturais decorrentes do tráfico de animais. Com o auxílio de sua equipe de trabalho Lyndal Davies consegue recuperar dezenas de chimpanzés por ano conforme se pode verificar em 2003, em Istambul (CAMPOS NETO, 2005).

O tráfico dos chimpanzés é realizado, desde 1966, de forma acirrada e sua intervenção tem facilitado no rastreamento de ações e rotas escolhidas por infratores e caçadores ilegais de animais, principalmente dos que atuam na África e Europa. Lyndal Davies e sua equipe têm atingido resultados positivos com o trabalho que desenvolvem. Além disso, atuam também no monitoramento e preservação do coala, na Austrália (CAMPOS NETO, 2005).

David Favre professor da Faculdade de Direito da Universidade Estadual de Michigan também se posiciona a 
favor da causa animal. Ele defende os direitos dos animais partindo da compreensão de que esses seres sencientes devem ser considerados uma categoria especial de propriedade. Para Favre os animais não são nem humanos e nem objetos inanimados e justamente por isso os direitos a eles reservados devem estar além dos institutos jurídicos, à primeira vista inconciliáveis, da propriedade e da pessoa jurídica, e atribuir aos animais um status jurídico parecido com ao dos escravos do início do século XIX nos EUA, que não obstante estarem desprovidos da titularidade dos direitos subjetivos, eram destinatários de uma proteção jurídica especial (FAVRE, 1983 apud SANTANA, 2006).

Partindo desse entendimento de Favre, o tutor do animal permanece como detentor do seu direito sobre tal animal, porém repassa ao próprio animal o título equitativo daquela propriedade, gerando desse modo uma nova e limitada forma de propriedade animal: a autopropriedade equitativa. E, nessa perspectiva tutor detém posição similar "a de um guardião dos interesses dos animais, representando-os judicial ou extrajudicialmente" (SANTANA, 2006, p.133-134).

No que se refere às Legislações, considera-se relevante ressaltar que a Legislação Protetiva dos Animais é originária de países estrangeiros e somente a posteriori foi consolidada no Brasil. "No Reino Unido, ao iniciar o século XX, surgiu a Lei de proteção aos animais, começando a se concretizar as garantias dos animais" (MURARO; ALVES, 2014, p.8).

Acrescenta-se também o fato de que a demarcação protetiva manifestou-se após edição da Declaração Universal dos Direitos dos Animais (MURARO; ALVES, 2014). Essa Declaração foi proclamada no dia 27 de janeiro de 1978 na sede da Organização das Nações Unidas para a Educação, Ciência e Cultura - UNESCO pela Liga Francesa de Direito Animal - LFDA (SANTANA, 2006).

A Declaração firmada por quase unanimidade dos países do mundo, incluindo o Brasil, apresenta alguns princípios básicos que se pode considerar, sob o aspecto moral, como uma Carta Magna dos Animais (UNESCO, 1978).

Ainda no que diz respeito à tutela animal no contexto mundial, outros cinco fatos merecem destaque. Primeiro fato: o crescimento do movimento em defesa dos animais após a década de 1970 com a criação de associações voltadas à discussão dos direitos dos animais como, por exemplo. Dentre elas cita-se (i) a fundação no ano de 1978 dos "Advogados pelos Direitos dos Animais" na Califórnia posteriormente reconhecida em 1984 como "Fundo de Defesa dos Animais" e a (ii) criação da People for the Ethical Treatment of Animals - PETA voltada à conscientização do sofrimento animal (SILVA, 2013, p. 38).

Esta primeira fase por direitos para os animais trouxe como consequência a "Marcha pelos Animais" em Washington no ano de 1990 e o "Fundo de Defesa dos Animais rapidamente se transformou em uma organização nacional voltada para o ativismo judicial em prol dos animais." (SILVA, 2013, p. 39).

A segunda fase por direitos para os animais ocorreu com a publicação do periódico idealizado por Henry Mark denominado Animal Rights Law repórter. Henry enquanto advogado em Nova York e militante por direitos para os animais, conseguiu por intermédio dessa publicação agregar advogados e estudantes de direito interessados na tutela animal os quais ofertando-lhe recursos financeiros e publicidade contribuíram para o desenvolvimento e crescimento dessa segunda fase por direitos para os animais (SILVA, 2013).

Segundo fato, no ano de 1989 "numa conferência realizada na Alemanha, foi aprovada a Proclamação dos Direitos dos Animais, que, diferentemente da Declaração Universal dos Direitos dos Animais, reivindica a total abolição da exploração institucionalizada dos animais." (SANTANA, 2006, p.112). Ressalta-se a relevância dos artigos $1^{\circ}$ e $2^{\circ}$ dessa Proclamação dos Direitos os Animais os quais evidenciam o seguinte: "Art. 1. O mais elementar princípio de justiça exige que semelhantes sejam tratados igualmente e desiguais sejam tratados de forma desigual. Todas as criaturas vivas devem ser tratadas de forma igual, em respeito aos aspectos em que são iguais". (PROCLAMAÇÃO..., 1989, p.1).

E o artigo $2^{\circ}$ por sua vez apresenta a seguinte redação: "Considerando que os animais, exatamente como as pessoas, esforçam-se por proteger suas vidas e as de suas espécies, e que demonstram interesse em viver, eles também têm direito à vida. Isto posto, não podem ser classificados como objetos ou semoventes, juridicamente". (PROCLAMAÇÃO..., 1989, p.1).

Embora, essas declarações de direitos se configurem como (i) conclusões ou resoluções proclamadas em conferencias internacionais por instâncias que não possuem personalidade jurídica e (ii) seus princípios e regras sejam destinados aos Estados participantes como simples responsabilidade política, considera a relevância delas no âmbito da tutela animal uma vez que por diversas vezes são mencionadas pelos tribunais nacionais (SANTANA, 2006).

Não obstante ao fato dessas declarações, tecnicamente, se configurarem com simples recomendações desprovidas, de força vinculante, as mesmas não dependem de declarações em constituições, leis ou tratados internacionais porque dizem respeito à dignidade do animal enquanto ser senciente e, portanto passíveis de serem colocadas em prática independentemente dos poderes oficiais sob a forma de indicativos de comportamentos a serem assumidos ou até mesmo como deslegitimadoras de orientações que lhes sejam antagônicas (SANTANA, 2006).

Ainda no que diz respeito à tutela animal no contexto mundial, um terceiro fato que merece destaque é que no ano de 1997 a União Europeia assinou em Amsterdam um Protocolo Protetivo e Bem-estarista Animal. No acordo existente entre os países da União Europeia foi acrescentado, por conseguinte mais um compromisso após o reconhecimento de que os animais são seres sencientes, possuindo sensibilidade e capacidade de experimentar o sofrimento e que, portanto, deveriam ser respeitados em prol de seu bem-estar. A 
assinatura desse Protocolo adensou, desse modo, a doutrina ética de Jeremy Benthan (MURARO; ALVES, 2014).

O quarto fato digno de reconhecimento no contexto mundial se refere à legislação francesa. Naquele país os crimes contra os animais foram extintos do capítulo destinado aos crimes contra o patrimônio, para inseri-los num capítulo à parte nominalmente tratado como "Outros Crimes". E um quinto fato é retratado na Alemanha em 2002 mediante aprovação de uma Emenda Constitucional para inclusão da tutela animal entre as responsabilidades vitais do Estado (SANTANA, 2006, p.156).

\subsubsection{A tutela animal no contexto das normatizações constitucionais brasileiras}

A Constituição Política do Império do Brasil de 1824, trata-se da primeira carta constitucional brasileira. O texto normativo foi produzido por intermédio de um conselho convocado pelo então imperador da época Dom Pedro I justamente para este fim, caracterizando-se, portanto por uma constituição outorgada (BRASIL, 1824). Nesta Constituição, nenhuma referência é realizada ao meio ambiente, muito menos a fauna e menos ainda a espécie animal doméstica.

A Constituição da República dos Estados Unidos do Brasil de 1891, composta por 91 artigos acrescidos de oito das disposições transitórias é considerada como a mais sintética de todas as Constituições da República (BRASIL, 1891) e nela também não foi encontrada nenhuma referência ao meio ambiente, muito menos a fauna e menos ainda a espécie animal doméstica.

A Constituição da República dos Estados Unidos do Brasil de 1934, trata-se da terceira constituição da história do Brasil, porém enquanto republicana é a segunda. Implementada no final do governo provisório de Getúlio Vargas (1930-34) com o objetivo de legitimar sua presidência e minimizar inquietações populares. Configura-se como a Constituição de menor período de vigência, entretanto de maior reflexo positivo para a posteridade no que diz respeito ao: sufrágio universal; fortalecimento do poder judiciário; e instituição de liberdades básicas e direitos trabalhistas (BRASIL, 1934). Não obstante avanços apresentados nesta Constituição, nenhuma referência é realizada ao meio ambiente, muito menos a fauna e menos ainda a espécie animal doméstica.

A Constituição da República dos Estados Unidos do Brasil de 1937 é reconhecida como "Polaca" porque continha leis de inspiração fascista assim como a Constituição Polonesa de 1935, tendo sido outorgada pelo presidente Getúlio Vargas. Na mesma data de sua promulgação (10 de novembro de 1937) foi instituída também a ditadura do Estado Novo. Constitui-se como a quarta Constituição do Brasil e a terceira da república a apresentar um texto normativo pretensamente democrático (BRASIL, 1937). Nela, nenhuma referência é realizada ao meio ambiente, muito menos a fauna e menos ainda a espécie animal doméstica.

A Constituição dos Estados Unidos do Brasil de 1946 foi promulgada. Os membros da Assembleia Constituinte, convocados por Eurico Gaspar Dutra, na época Presidente da República, promulgou após a derrocada do Estado Novo em 1945, a Constituição dos Estados Unidos do Brasil e o Ato das Disposições Constitucionais Transitórias no dia 18 de setembro de 1946, consolidando as liberdades instituídas na Constituição de 1934 e acrescentando novos direitos. Trata-se da quinta constituição brasileira, a quarta republicana e terceira de conteúdo republicano-democrático (BRASIL, 1946). Nesta Constituição também nenhuma referência é realizada ao meio ambiente, muito menos a fauna e menos ainda a espécie animal doméstica.

A Constituição da República Federativa do Brasil de 1967 se apresenta como a sexta Constituição brasileira e quinta no contexto da república, além de se configurar como segunda e última constituição republicana caracterizada como autoritária. Sua elaboração ocorreu sob vigilância dos militares que ocupavam o poder na ocasião. O texto constitucional: voltava-se à ratificação do regime deflagrado pelo Golpe de 1964; afastava-se do aspecto democrático; centrava-se no âmbito autocrático focando o poder no executivo; normatizava a ditadura militar no cenário nacional; apresentava-se como o mais coercitivo de todos os textos constitucionais; consentia a supressão de partidos políticos; e acresceu-se de muitas emendas, decretos-lei e atos institucionais sendo que estes se afiguraram como o texto da Emenda Constitucional elaborada em 1969 (BRASIL 1967, 1969). Nesta Constituição, bem como na Emenda Constitucional de 1969 também nenhuma referência é realizada ao meio ambiente, muito menos a fauna e menos ainda a espécie animal doméstica.

É importante ressaltar que a não positivação da temática tutela animal nas Constituições anteriores a de 1988 não significa completa ausência do assunto no âmbito infraconstitucional brasileiro uma vez que algumas normatizações neste sentido já existiam como, por exemplo, a Lei n 4.717 de 1965 que regulamenta a Ação Popular, a Lei $n^{\circ} 6.938$ de 1981 que dispõe sobre a Política Nacional do Meio Ambiente e a Lei 7.347 de 1985 que disciplina a Ação Civil Pública de responsabilidade por danos causados ao meio ambiente (BRASIL, 1965, 1981, 1985).

À primeira vista pode-se pensar que a Lei infraconstitucional $n^{\circ} 4.717$ de 1965 , a qual não evidencia em seu texto normativo nenhuma expressão do tipo "meio ambiente", "proteção do meio ambiente", "tutela animal" e menos ainda "tutela do animal doméstico", não tenha nada a contribuir com o adensamento da reflexão sobre o tema tratado neste artigo (BRASIL, 1965).

Entretanto, considera-se pertinente sua citação porque esta Lei regulamentadora da Ação Popular pode ser interpretada como protetiva do meio ambiente na medida em que no caput de seu artigo $1^{\circ}$ trata da anulação ou declaração de nulidade de atos lesivos ao patrimônio público, entendendo que uma das diversas dimensões deste patrimônio público se refere 
justamente ao meio ambiente. Além disso, a pertinência desta Lei no trato das questões ambientais é evidenciada na Constituição Federal de 1988 ao considerá-la como um dos diversos e importantes instrumentos jurídicos de tutela das liberdades públicas e de defesa ambiental (BRASIL, 1965, 1988).

A concretização da garantia de acesso ao direito fundamental previsto no artigo 225 da Constituição Federal qual seja de que: "Todos têm direito ao meio ambiente ecologicamente equilibrado, bem de uso comum do povo e essencial à sadia qualidade de vida [...]" (BRASIL, 1988) pode se dar, por exemplo, por meio de um mecanismo jurídico denominado Ação Popular. E nesse sentido, o inciso LXXIII do artigo $5^{\circ}$ da Constituição Federal é bastante enfático ao dispor que: "Qualquer cidadão é parte legítima para propor ação popular que vise anular ato lesivo ao patrimônio público ou de entidade de que o Estado participe, à moralidade administrativa, ao meio ambiente e ao patrimônio histórico e cultural [...]" (BRASIL, 1988).

Portanto, a Ação Popular, regulamentada pela Lei infraconstitucional $n^{\circ} 4.717$ de 1965 , apresenta-se como um importante instrumento legal do qual o cidadão pode fazer uso para propor anulação de um ato omissivo ou comissivo prejudicial ao animal doméstico residente no contexto urbano, por exemplo. (BRASIL, 1965).

No que tange à Lei infraconstitucional no 6.938 de 1981 se verifica, por exemplo, a presença da tutela animal. A princípio tal constatação pode ser percebida no artigo $3^{\circ}$ o qual apresenta a seguinte redação: "Para os fins previstos nesta Lei, entendese por: I - meio ambiente, o conjunto de condições, leis, influências e interações de ordem física, química e biológica, que permite, abriga e rege a vida em todas as suas formas [...]" (BRASIL, 1981). Portanto, considerar que o meio ambiente abriga a vida significa compreender que o meio ambiente também abriga a espécie animal e por consequência, tutelálo é sinônimo de tutela animal. E nesse mesmo artigo, no inciso III reforça-se tal proteção animal quando se reconhece como "[...] poluição, a degradação da qualidade ambiental resultante de atividades que direta ou indiretamente: [...] c) afetem desfavoravelmente a biota [entendida como conjunto de todos os seres vivos de uma região, portanto não somente o ser humano, mas também o animal]". Na sequência, o artigo $15^{\circ}$ informa que: "O poluidor que expuser a perigo a incolumidade [...] animal [...] ou estiver tornado mais grave situação de perigo existente, fica sujeito à pena de reclusão [...] e multa [...]". Por fim, no parágrafo $1^{\circ}$ deste mesmo artigo lê-se que: "a pena é aumentada até o dobro se: I- resultar: a) dano irreversível à fauna [...]" (BRASIL, 1981).

Com relação à Lei 7.347/1985, embora essa normatização federal infraconstitucional não foque exclusivamente da tutela animal e particularmente do animal doméstico, mas sim do meio ambiente como um todo, ela merece destaque, assim como foi realizado com a Lei regulamentadora da Ação Popular supracitada, justamente porque, não obstante ser essencialmente instrumental, apresenta um rol normativo de procedimentos processuais toda vez que houver lesão ou ameaça de lesão ao meio ambiente (BRASIL, 1985).

Denominada de Ação Civil Pública, apesar de tratar também de lesão ou ameaça de lesão ao consumidor, aos bens e direitos de valor artístico, estético, histórico, turístico e paisagístico, essa Lei é importante no sentido de ser um instrumento de defesa, dentre outros, também do meio ambiente (BRASIL, 1985).

A Constituição da República Federativa do Brasil de 1988 corresponde ao contemporâneo Texto Normativo brasileiro e apresenta-se como a: (i) sétima Carta Magna nacional; (ii) sexta da república federativa; e (iii) última a alicerçar a trajetória de um regime autoritário - a Ditadura Militar de 1964 a 1985 - para um regime democrático, caracterizado como Nova República iniciada em 1985 e permanecendo até a atualidade. Esta Constituição foi: (a) promulgada, ou seja, contou com a participação ativa da totalidade da sociedade em sua elaboração; e (b) produzida por uma Assembleia Constituinte composta por 559 parlamentares de distintas ideologias políticas, portanto dogmática. Trata-se de um documento (i) formal e escrito - uma estrutura delineada por regras; e (ii) analítico e rígido - texto pormenorizado e alterado somente por emendas constitucionais. Esta Constituição é também denominada de "Constituição Cidadã" e recebeu este cognome por se tratar de um texto muito completo no que se refere às garantias individuais: Esta Carta Magna nacional: (a) restabelece a inviolabilidade de (i) direitos, (ii) garantias fundamentais e (iii) liberdades básicas; (b) consagra uma grande quantidade de disposições progressistas, dos quais destacam-se a: (i) vedação completa do ato de tortura, (ii) criminalização do racismo, (iii) igualdade de gêneros; (c) institui direitos sociais para a totalidade da sociedade como por exemplo: (i) educação, (ii) saúde, (iii) alimentação, (iv) trabalho, (v) moradia, (vi) transporte, (vii) lazer, (viii) segurança, (ix) previdência social, (x) proteção à maternidade e à infância, e (xi) assistência aos desamparados (BRASIL, 1988).

Nesta Constituição, ao contrário das seis anteriores, é possível encontrar referência: (a) ao meio ambiente considerado como mais um dos direitos fundamentais elencados no texto normativo nacional ao positivar que: "Todos têm direito ao ambiente ecologicamente equilibrado"; (b) à fauna nacional de forma geral não se restringindo apenas a espécie animal doméstica; (c) à proteção desta fauna mediante proibição de práticas potencialmente perigosas (i) às funções ecológicas dos animais, (ii) à continuidade de sua existência (extinção de espécies), (iii) e à manutenção de sua integridade física e mental (proibição da submissão dos animais a crueldade); (d) e à previsão de imposição de sansões civis, penais e administrativas às pessoas físicas ou jurídicas que por ação ou omissão submeterem os animais a situações lesivas (BRASIL, 1988).

$\mathrm{Na}$ Constituição Federal de 1988 merece destaque no 
que se refere à temática da Tutela Animal o que se encontra positivado no capítulo VI que trata do meio ambiente em seu artigo 225 acompanhado pelos seus diversos parágrafos e incisos. No artigo 225 lê-se: "Todos têm direito ao meio ambiente ecologicamente equilibrado, bem de uso comum do povo e essencial à sadia qualidade de vida, impondo-se ao poder público e à coletividade o dever de defendê-lo e preservá-lo para as presentes e futuras gerações" (BRASIL, $1988, \mathrm{~s} / \mathrm{p}$., grifo nosso). No parágrafo $1^{\circ}$, inciso I destacase a responsabilidade do Poder Público no que se refere a assegurar a efetividade desse direito mediante preservação e restauração dos processos ecológicos vitais, bem como por meio do provimento do manejo ecológico das espécies e neste sentido entende-se espécies como todo ser vivo existente no planeta e, portanto, também o animal.

Outro inciso do mesmo artigo e mesmo parágrafo que merece destaque neste estudo referente Tutela Animal é o de $\mathrm{n}^{\mathrm{o}}$ VII o qual apresenta a seguinte redação: “[...] proteger a fauna e a flora, vedadas, na forma da lei, as práticas que coloquem em risco sua função ecológica, provoquem a extinção de espécies ou submetam os animais a crueldade". (BRASIL, 1988). Neste inciso a questão da proteção animal é evidenciada de forma direta, clara e transparente e não deixa margem de dúvidas sobre a relevância da Tutela Animal e consequentemente da tutela do animal doméstico também no âmbito constitucional.

Ainda com relação ao artigo 225 , parágrafo $1^{\circ}$, inciso VII é relevante evidenciar que o legislador, não obstante autorizar a tutela de direitos individuais, o que já era realizado, passou a admitir também a tutela de direitos coletivos, e isso justamente porque se compreendeu e se assimilou a existência de uma terceira espécie de bem: o bem ambiental. Portanto, os direitos ambientais se configuram como direitos difusos quais sejam direitos de natureza indivisível, que pertence a todos, ao mesmo tempo, porém ninguém em particular o possui (BRASIL, 1988). E tal realidade abriu caminhos para se conceber por consequência a tutela animal visto que o meio ambiente é compreendido, dentre outras definições complementares como aquele contexto que abriga e rege a vida em todas as suas formas (BRASIL, 1981).

Por fim, o parágrafo $3^{\circ}$ do mesmo artigo evidencia as consequências penais, administrativas e civis atreladas ao comportamento ativo ou omissivo, tanto por parte da pessoa física ou jurídica, no que se refere ao descumprimento da tutela animal prevista constitucionalmente conforme se pode verificar a seguir: "As condutas e atividades consideradas lesivas ao meio ambiente sujeitarão os infratores, pessoas físicas ou jurídicas, a sanções penais e administrativas, independentemente da obrigação de reparar os danos causados." (BRASIL, 1988, s/p.).

A partir da positivação da temática Tutela Animal no âmbito constitucional (BRASIL, 1988), verificou-se a instauração de um processo que paulatinamente contribuiu para: (i) a amplificação - na ambiência societária brasileira - de espaços para reflexão sobre a relevância de se conceber a espécie animal como digna de defesa e proteção; bem como para (i) implementação no plano infraconstitucional de novas e contínuas normatizações que tratam da temática como, por exemplo, as Leis Federais $n^{\circ} 7.802 / 89$, 9.433/97, 9.605/98, 12.651/2012, 13.426/2017, o Decreto Federal no 6.514/2008, a Lei Federal Complementar ${ }^{\circ} 140 / 2011$ e o Projeto de Lei Federal $n^{\circ} 4.564 / 2016$ que se encontra em tramitação na Câmara dos Deputados Federais (BRASIL, 1989, 1997, 1998, 2008, 2011, 2012, 2016, 2017).

\section{Conclusão}

Conclui-se que o atual estágio defensivo e protetivo em que se encontra a espécie animal na conjuntura nacional brasileira é consequência da evolução normativa tanto no plano constitucional como infraconstitucional.

Os delineamentos, os limites, bem como os avanços na conquista da tutela animal e consequentemente do animal doméstico demonstram o quanto o reconhecimento de tal questão é socialmente construído. Além disso, a expansão, a solidificação e o desenvolvimento contínuo também da vida humana e da sociedade implicam necessariamente na preservação e na ampliação de acesso um direito fundamental nominalmente reconhecido pela Constituição Federal de 1988 como direito ao ambiente ecologicamente equilibrado no qual se insere evidentemente a fauna, ou seja, os animais domésticos, domesticados, silvestres e exóticos.

\section{Referências}

BÍBLIA. Português. Bíblia Sagrada: Novo e Velho Testamento. São Paulo: Ave Maria, 1998.

BRASIL. Constituição (1824). Constituição Política do Império do Brasil: outorgada em 25 de março de 1824. Rio de Janeiro, 1824.

BRASIL. Constituição (1891). Constituição da República dos Estados Unidos do Brasil: promulgada em 24 de fevereiro de 1891. Rio de Janeiro, 1891.

BRASIL. Constituição (1934). Constituição da República dos Estados Unidos do Brasil: promulgada em 16 de julho de 1934. Rio de Janeiro, 1934.

BRASIL. Constituição (1937). Constituição da República dos Estados Unidos do Brasil: outorgada em 10 de novembro de 1937. Rio de Janeiro, RJ, 1937.

BRASIL. Constituição (1946). Constituição dos Estados Unidos do Brasil: promulgada em 18 de setembro de 1946. Rio de Janeiro, RJ, 1946.

BRASIL. Presidência da República. Casa Civil. Lei 4.717, 29 de junho de 1965. Dispõe sobre a regulação da Ação Popular. Brasília, DF, 1965.

BRASIL. Constituição (1967). Constituição da República Federativa do Brasil: autoproclamada como promulgada em 24 de janeiro de 1967. Brasília, DF, 1967.

BRASIL. Presidência da República. Lei Federal 6.938, de 31 de agosto de 1981. Dispõe sobre a Política Nacional do Meio Ambiente, seus fins e mecanismos de formulação e aplicação, e dá outras providências, Brasília, DF, 1981. 
BRASIL. Presidência da República. Casa Civil. Lei 7.347, 24 de julho de 1985. Dispõe sobre o disciplinamento da Ação Civil Pública de responsabilidade por danos causados ao meio ambiente, ao consumidor, a bens e direitos de valor artístico, estético, histórico, turístico e paisagístico e dá outras providências. Brasília, DF, 1985.

BRASIL. Constituição (1988). Constituição da República Federativa do Brasil: promulgada em 05 de outubro de 1988. Brasília, DF, 1988.

BRASIL. Presidência da República. Casa Civil. Lei 7.802, 11 de julho de 1989. Dispõe sobre a pesquisa, a experimentação, a produção, a embalagem e rotulagem, o transporte, o armazenamento, a comercialização, a propaganda comercial, a utilização, a importação, a exportação, o destino final dos resíduos e embalagens, o registro, a classificação, o controle, a inspeção e a fiscalização de agrotóxicos, seus componentes e afins, e dá outras providências. Brasília, DF, 1989.

BRASIL. Presidência da República. Lei Federal 9.433, de 08 de janeiro de 1997. Dispõe sobre a instituição da Política Nacional de Recursos Hídricos, cria o Sistema Nacional de Gerenciamento de Recursos Hídricos, regulamenta o inciso XIX do artigo 21 da Constituição Federal, e altera o artigo $1^{\circ}$ da Lei $n^{\circ} 8.001$, de 13 de março de 1990, que modificou a Lei $\mathrm{n}^{\circ} 7.990$, de 28 de dezembro de 1989, Brasília, DF, 1997.

BRASIL. Presidência da República. Casa Civil. Lei 9.605, 12 de fevereiro de 1998. Dispõe sobre as sanções penais e administrativas derivadas de condutas e atividades lesivas ao meio ambiente, e dá outras providências. Brasília, DF, 1998.

BRASIL. Presidência da República. Casa Civil. Decreto Lei $6.514,22$ de julho de 2008. Dispõe sobre as infrações e sanções administrativas ao meio ambiente, estabelece o processo administrativo federal para apuração destas infrações, e dá outras providências. Brasília, DF, 2008.

BRASIL. Presidência da República. Casa Civil. Lei Complementar 140, de 08 de dezembro de 2011. Dispõe sobre a fixação de normas, nos termos dos incisos III, VI e VII do Caput e do Parágrafo Único do Artigo 23 da Constituição Federal, para a Cooperação Entre a União, os Estados, o Distrito Federal e os Municípios nas Ações Administrativas Decorrentes do Exercício da Competência Comum Relativas a Proteção das Paisagens Naturais Notáveis, a Proteção do Meio Ambiente, ao Combate a Poluição em Qualquer de Suas Formas e a Preservação das Florestas, da Fauna e da Flora; e Altera a Lei 6.938, de 31 de Agosto de 1981. Brasília, DF, 2011.

BRASIL. Presidência da República. Casa Civil. Lei 12.651, 25 de maio de 2012. Dispõe sobre a proteção da vegetação nativa; altera as Leis nos 6.938 , de 31 de agosto de 1981, 9.393, de 19 de dezembro de 1996, e 11.428, de 22 de dezembro de 2006; revoga as Leis nos 4.771, de 15 de setembro de 1965, e 7.754, de 14 de abril de 1989, e a Medida Provisória no 2.166-67, de 24 de agosto de 2001; e dá outras providências. Brasília, DF, 2012.

BRASIL. Câmara dos Deputados. Projeto de Lei PL 4.564/2016. Dispõe sobre a conduta de maus-tratos praticada contra os animais e estabelece punição. Disponível em: <http://www.camara.gov. $\mathrm{br} /$ proposicoesWeb/fichadetramitacao idProposicao $=2078280>$. Acesso em: 01 out. 2019.

BRASIL. Presidência da República. Casa Civil. Lei 13.426, 30 de março de 2017. Dispõe sobre a Política de Controle da Natalidade de Cães e Gatos e dá outras providências. Brasília, DF, 2017.

CAMPOS NETO, A.A.M. O direito dos animais. 2005. Disponível em: <www.revistas.usp.br/rfdusp/article/download/67625/70235 $>$. Aceso em: 1 out. 2019.

FRANCO, E.C. A violência e a tortura de animais revela desvio de personalidade. Rev. Jusbrasil, p.1-9, 2016.

LEVAI, L.F. Direitos dos Animais: o direito deles e o nosso direito sobre eles. Campos do Jordão: Mantiqueira, 1998.

MURARO, C.C.; ALVES, D.N. Maus tratos de cães e gatos em ambiente urbano, defesa e proteção aos animais. Rev. Âmbito Jurídico, v.17, n.122, p.1-51, 2014.

PENSADOR. Biografia de Albert Schweitzer. Disponível em: $<$ https://www.pensador.com/autor/albert_schweitzer/biografia/>. Acesso em: 1 out. 2019.

PROCLAMAÇÃO DOS DIREITOS DOS ANIMAIS. 1989. Disponível em: <dhttp://www. geocities.ws/direitosanimais21/ anexo2.htm>. Acesso em: 1 out. 2019

PEROVANO, D.G. Manual de metodologia da pesquisa científica. Curitiba: Intersaberes, 2016.

SANTANA, H.J. Abolicionismo animal. 2006. 281f. Tese (Doutorado em Direito) - Universidade Federal de Pernambuco, Recife. 2006.

SÃO PAULO. Assembleia Legislativa de São Paulo. Lei Estadual $\mathrm{n}^{\mathrm{o}} 11.977$, de 25 de agosto de 2005. Dispõe sobre a instituição do Código de Proteção aos Animais do Estado e dá outras providências. São Paulo, SP, 2005.

SILVA, T.T.A. Direito animal e ensino jurídico: formação e autonomia de um saber pós-humanista. 2013. 192f. Tese (Doutorado em Direito) - Universidade Federal da Bahia, Salvador. 2013.

UNESCO. Declaração Universal dos Direitos dos Animais. Bruxelas: UNESCO, 1978. 